\title{
O Princípio da Dignidade Humana e suas Projeções no Âmbito Laboral: possibilidades e limites
}

\author{
The Principle of Human Dignity and its Projections in the Workplace: \\ possibilities and limits
}

\author{
Ipojucan Demétrius Vecchi ${ }^{1}$ \\ Marcos Leite Garcia \\ Liton Lanes Pilau Sobrinho ${ }^{2}$ \\ ${ }^{1}$ Universidade de Passo Fundo, Passo Fundo, RS, Brasil \\ ${ }^{2}$ Universidade do Vale do Itajaí, Itajaí, SC, Brasil
}

Resumo: O objetivo do presente estudo é analisar a dignidade da pessoa humana de acordo com suas projeções no mundo do trabalho. Para tanto, será abordada a noção de dignidade da pessoa humana no campo jurídico desde a sua positivação constitucional e seus efeitos nas relações entre capital e trabalho. Por fim, serão vistos os limites estruturais para a incidência da dignidade humana nas relações de trabalho. O método utilizado para a pesquisa é o indutivo. Conclui-se que a dignidade humana indica várias limitações salutares ao cidadão trabalhador.

Palavras-chave: Dignidade. Pessoa Humana. Trabalho. Positivação Constitucional. Cidadão.
Abstract: The objective of the present study is to analyze the dignity of the human person according to their projections in the world of work. In order to do so, the notion of human dignity in the juridical field will be approached from its constitutional positivation and its effects on the relations between capital and labor. Finally, the structural limits for the incidence of human dignity in labor relations will be seen. The method used for the research is the inductive one. At the end of the article it is verified that human dignity indicates several salutary limitations to the working citizen.

Keywords: Dignity. Human Person. Work. Constitutional Positivation. Citizen.

Recebido em: 16/03/2020

Revisado em: 17/07/2020

Aprovado em: 03/08/2020 


\section{Introdução}

O presente texto tem como objetivo analisar a ideia de dignidade, sua constituição histórica, filosófica e jurídica, para, então, perscrutar de suas potencialidades e eventuais limites de consideração no âmbito as relações de trabalho subordinado.

O princípio da dignidade humana é considerado como um dos cernes dos ordenamentos jurídicos contemporâneos, tanto em nível internacional como interno. Sua importância para a práxis jurídica é imensurável, o que também só ocorrer no campo das relações de trabalho subordinadas. O problema é como aplicar a dignidade da pessoa em todos os âmbitos. Assim, o presente trabalho tem como justificativa a questão da dignidade da pessoa humana relacionada com suas projeções no âmbito laboral, suas possibilidades e limites. Dessa maneira, a dignidade humana será também desenvolvida no âmbito social, a partir da defesa de uma vida digna do cidadão.

A metodologia da pesquisa foi desenvolvida mediante leitura pelo método indutivo. Trata-se de pesquisa básica, exploratória e bibliográfica, estruturada em quatro fragmentos. Para tanto, num primeiro momento, far-se-á um breve escorço histórico da ideia de dignidade humana, perpassando da filosofia moral ao direito. Num segundo momento, abordar-se-á a noção de dignidade humana propriamente no campo jurídico, sua positivação constitucional e efeitos. Posteriormente, analisar-se-á os eventuais reflexos do princípio da dignidade humana no campo trabalhista. Por fim, serão abordados os possíveis limites estruturais para a plena incidência da dignidade humana nas relações de trabalho subordinadas.

\section{Histórico da Ideia de Dignidade, da Filosofia Moral ao Direito}

Talvez um dos erros mais comuns nas análises socioeconômicas, políticas e jurídicas é aquele que se consubstancia na adoção de uma postura que se apega a um termo, uma palavra, uma locução, desconectada de sua origem histórica, de seu contexto, dando-lhe um caráter de eternidade, deixando-se, assim, de se verificar e se analisar o caráter específico 
que um referido termo, palavra ou locução, representa em cada formação social. Com a ideia de dignidade humana, não é diferente.

Como tudo que é humano é marcado pela historicidade, também a noção de dignidade humana não pode escapar desse crivo histórico. A ideia de dignidade humana surge no processo de transformações socais e históricas que marcam a humanidade, essa ideia aparece também no campo jurídico apenas na modernidade.

Iñigo de Miguel Beriain (2004, p. 189) afirma que a origem da palavra dignidade provém do sânscrito, com raiz dec e com o sentido de conveniente, adequado, conforme a algo ou alguém. Posteriormente, tendo sido adotada pelas línguas latinas, à referida palavra foi acrescentado o sufixo mus, formando o vocábulo decmus, acabando por derivar em dignus e dignidade. Segundo o autor, a palavra "dignidade" tinha duas conotações, dois sentidos. Numa primeira conotação, a palavra dignidade era utilizada no sentido de reconhecer um aspecto diferenciado, superior, a alguém em razão de sua posição social, a um cargo políticos eclesiásticos ou honorífico. Assim, em todas essas situações, a ideia de dignidade está atrelada a algo externo à própria pessoa, estando associada às circunstâncias sociais, políticas, econômicas, que lhe conferem uma distinção em relação aos demais. Junto a esse primeiro sentido, surgiu outro, especialmente a partir da filosofia estoica e do cristianismo, que jungiu a ideia de dignidade ao campo do ser (da pessoa), no sentido de considerar a pessoa humana como centro do cosmos (estoicismo) ou como criada à imagem e semelhança de Deus (cristianismo). Sustenta o autor, que após um certo colapso dessa concepção durante a Idade Média, com o Renascimento, a ideia de dignidade assume caráter de grande importância na discussão da filosofia, muito embora sempre estando vinculada a ideia de dignidade com uma razão teológica (em razão de ser o homem criado à imagem e semelhança de Deus).

Assim com o advento do Direito Racional Racionalista (iusracionalismo) ${ }^{1}$, a partir de autores como Christian Tomasius, Christian

\footnotetext{
${ }^{1}$ Sobre o tema do Direito Natural Moderno, ou direito natural racionalista, veja-se o argumento de Jürgen Habermas (2008, p. 87-162) sobre o fato de ser o acontecimento mais importante da história da humanidade.
} 
Wolf, Samuel Pufendorf (GARCIA, 2005a), as reflexões e as reivindicações sobre a tolerância religiosa, humanização do direito penal e do processo penal e limitação do poder do Estado, todas categorias relacionadas com a dignidade da pessoa humana, irão contribuir para o desenvolvimento dos ideais de liberdade. Ademais serão desenvolvidos posteriormente por autores como Beccaria e Voltaire (PECES-BARBA, 2003, p. 38-64), e que terão na obra de Immanuel Kant o seu ponto de convergência e complementação. Da mesma forma, argumenta De Miguel Beriain (2004, p. 192-193):

Será, no obstante, el genio de Kant el que dotará al concepto de uma nueva dimensión, moldeando sus antiguos rasgos con otros incorporados por él impulsándolo de esta manera hacía la posición de privilegio que ahora ocupa. A Kant se deben, entre otras, la idea de que lo digno es aquello que no tiene precio, o que la humanidade e sen sí misma uma dignidad, pensamientos que vienen a convertir a la dignidad en una idea clave dentro de su sistema moral.

De igual maneira, a dignidade será desenvolvida pelos filósofos da Ilustração francesa, como o Barão de Montesquieu e Jean-Jacques Rousseau. Então, De Miguel Berain (2004, p 193) conclui o seguinte:

[...] la noción de dignidad influirá sobremanera en los trabajos de, entre otros, Jean Jacques Rousseau o Fichte, para luego, ya a finales del siglo, entrar a formar parte de las recopilaciones de los enciclopedistas franceses y de las declaraciones de derechos propias del período histórico en cuestión.

Posteriormente, a influência do conceito de dignidade humana irá se deixar sentir inclusive dentro das fileiras dos movimentos marxista, já que a ideia será compartilhada e considerada um ponto de partida e de chegada dos direitos fundamentais de todo ser humano, nas palavras de Gregorio Peces-Barba ${ }^{2}$, professor e líder socialista espanhol. Uma vez

\footnotetext{
${ }^{2}$ Para determinar o caminho filosófico percorrido pela dignidade da pessoa humana como ponto de partida e de chegada dos direitos fundamentais, Gregorio Peces-Barba chama a atenção para os ensinamentos da história. Em seu escrito sobre o tema, o autor madrilenho
} 
que seja através da linha tradicional que considera a alienação trabalhista como o reverso da dignidade humana ${ }^{3}$ por meio de uma variante explícita na obra de Ernest Bloch (2011), que defende a tese de que o direito natural, reduzido já quase que exclusivamente ao postulado da defesa da dignidade da pessoa humana, tem sido durante séculos o autêntico referente da defesa dos direitos humanos (DE MIGUEL BERAIN, 2004, p. 193).

Como se pode perceber, a ideia de dignidade humana sofre profundas alterações em seu sentido ao longo das alterações socioeconômicas, políticas e jurídicas ocorridas ao longo da história, não se podendo falar de um conceito trans-histórico de dignidade, igualando a noção moderna de dignidade humana ao seu sentido original clássico ou mesmo no medievo.

No que diz respeito ao sentido da dignidade humana kantiano e nas reivindicações posteriormente levadas a cabo pelas revoluções igualitárias e socialistas, de modo particular no que diz respeito aos autores de inspiração marxista, cumpre destacar que não há como afirmar - e muito menos de modo generalizado - que estes estejam propriamente negando a dignidade da pessoa humana ou seu reconhecimento. Para comprovar tal afirmação faz-se fundamental citar a expressiva obra, escrita em 1961, Naturrech und menscliche Würde do filósofo alemão e humanista marxista Ernest Bloch $(2011)^{4}$ que, embora tenha considerado a liberda-

nos faz lembrar que "[...] a ideia de dignidade, como todos os demais que tratamos no âmbito da cultura moral, política e jurídica, são construções do pensamento humano" (PECES-BARBA, 1994, p. 319). Essa interpretação do que o professor Gregorio PecesBarba quer dizer, sobre a dignidade humana ser o ponto de partida e ao mesmo tempo o ponto chegada dos direitos humanos, significa que: $1^{\circ}$ ) a dignidade da pessoa humana deve ser teoricamente considerada como fundamento dos direitos humanos, desde a igualdade, e, por isso, seu ponto de partida; $2^{\circ}$ ) a dignidade da pessoa humana deve ser averiguada na prática para ver se houve uma violação de direitos humanos, desde a igualdade. Enfim, se foi violado um direito fundamental, deve-se ver se foi violada a dignidade da pessoa humana, e, por isso, depois de um longo caminho filosófico teórico e prático, o ponto de chegada dos direitos humanos.

${ }^{3}$ Aqui nos recorda o eterno repetir do trabalho, operário ou não, e o sem sentido da vida na obra de Albert Camus, O mito de Sísifo (2020).

${ }^{4}$ Aqui em questão utiliza-se a tradução de Felipe González Vicén ao espanhol da obra de Ernest Bloch (2011). 
de e a igualdade ilusões do iusnaturalismo burguês, e mesmo afirmando a negativa da existência de direitos naturais no sentido de inatos, destaca o importantíssimo fato histórico que todos os direitos humanos foram conquistados pelas lutas reivindicatórias. Certamente que pode-se afirmar que significam as lutas dos movimentos sociais e populares como reivindicações dos Direitos dos mais débeis, conceito de grupo dos mais fracos desenvolvido por Luigi Ferrajoli (1999) e Gregorio Peces-Barba (1994). Assim, Bloch e os autores de sua linha de pensamento reconhecem uma vontade para a liberdade e dignidade, além de que dita corrente acaba elaborando uma fundamentação crítica e marxista da dignidade, sem nenhuma dúvida importantíssima para o desenvolvimento dos direitos humanos e da dignidade humana no contexto contemporâneo.

No contexto do presente artigo, a projeção da dignidade humana no âmbito dos direitos fundamentais sociais deve ser considerada como uma continuação no relato cronológico de acontecimentos da dignidade da pessoa humana, assentada inicialmente no consenso proposto por Immanuel Kant e desenvolvida no contexto das reivindicações dos grupos mais vulneráveis de cada momento histórico da modernidade/contemporaneidade, que se dá nas relações sociais dos oprimidos com os mais fortes e opressores. Assim, o grupo dos mais débeis que reivindicam Direitos e que exigem que seja reconhecida sua dignidade será inicialmente o grupo de burgueses e sans culottes, depois os trabalhadores ou proletários e, posteriormente, as minorias sociológicas, como as mulheres, idosos, crianças, consumidores etc. E hoje em dia há também outros tipos de minorias, como alguns grupos de oprimidos da atualidade e as especificações de conteúdo como as relacionadas com o meio ambiente, a sustentabilidade, a bioética, as novas tecnologias etc. Cada momento histórico tem a sua própria exigência de melhoria das condições dignas de vida. Para tal, adotou-se as linhas de evolução teórica dos direitos fundamentais e da dignidade humana, propostas por Noberto Bobbio (1992, p. 67-83) e desenvolvidas por Gregorio Peces-Barba (1995, p. 154-205): marcadas pelos seguintes processos de positivação, generalização, internacionalização e especificação. Confirmando assim que os direitos sociais, incluindo os direitos trabalhistas, educação, saúde pública e também a democracia do sufrágio universal, se desenvolverão no processo de generalização ao 
longo do século XIX e serão primeiramente positivados nas constituições do início do século XX: México de 1917 e Alemanha de 1919. E reconstruídas a partir das constituições do pós-guerra: Itália de 1948, Alemanha de 1949, França de 1958, Portugal de 1976, Espanha de 1978 etc. Nesse caminho segue a nova visão social da dignidade da pessoa humana com a inclusão - generalização - de todos os seres humanos, ou seja, todos os membros da sociedade humana.

Portanto, como sustenta Eduardo Ramalho Rabenhorst (2010, p. 25-28), a noção de dignidade e, também, a própria ideia de humanidade não se fazem presentes no pensamento clássico. Aliás, segundo o autor, também a ideia de "gênero humano" só se delineia de forma mais nítida na modernidade. $\mathrm{O}$ autor sustenta que, no mundo antigo, a ideia de dignidade estava vinculada à honra, ao mérito, a uma função, posição social ou ofício desempenhado por alguém. Fundamentado em Jean-François Mattei, Rabenhorst (2010, p. 28) afirma que:

[...] o adjetivo latino "dignus" que também se refere às qualidades particulares de um indivíduo que suscitam estima, prestígio ou mérito. A propósito, [...] a palavra latina dignitas tem um caráter nitidamente aristocrático. Pertencer à nobreza romana, desempenhar um cargo político ou ter antepassados ilustres é o que confere dignidade aos indivíduos. Mesmo em Cícero, o termo dignitas guarda esse sentido de excelência, grandeza ou eminência, ainda que o ilustre pensados romano tenha se aproximado do conceito cristão de dignidade ao afirmar que o valor do homem decorre de suas semelhanças com os deuses, principalmente no que concerne à capacidade de discernir o justo do injusto.

Assim, é possível dizer que a dignidade da pessoa humana na atualidade é um conceito que vem se esboçando a partir da modernidade ou das transformações da sociedade antes da era da modernidade. Dessa forma, somente no trânsito para a modernidade, como sustenta Gregorio Peces-Barba (2005, p. 23-24), é que a reflexão sobre a dignidade humana no campo da filosofia do direito se torna plena, tendo por suporte a ideia do homem como centro do mundo e centrado no mundo, estando tal concep- 
ção marcada pelo antropocentrismo e pela laicização e não mais por um aspecto predominantemente teológico.

Marcos Leite Garcia (2005b, p. 21-22), na esteira do pensamento de Gregorio Peces-Barba, sustenta que é no trânsito para a modernidade, em meio às transformações socioeconômicas e políticas que marcam a passagem do medievo para o mundo moderno, que a ideia moderna de dignidade humana se constituiu como ideia fonte para o desenvolvimento da filosofia dos direitos fundamentais. Garcia (2005b, p. 22) afirma que:

Ao longo do período em questão é quando se formará a filosofia dos direitos fundamentais, assim chamada pelo professor Peces-Barba, como aproximação moderna da dignidade humana, em meio das feições características das mudanças que se influem e se entrelaçam. Estas se dariam resumidamente nos campos da economia, da política e da mudança de mentalidade. A profunda mudança na situação econômica com o surgimento e progressivo amadurecimento do capitalismo e com o crescente protagonismo da burguesia, favorecerá a mentalidade individualista diante da visão do homem em estamentos. No campo político o pluralismo do poder será substituído pelo Estado como forma de poder racional centralizado e burocratizado. O Estado é soberano, na construção doutrinal que se inicia com Jean Bodin, ou seja, o Estado não reconhece superior e tem o monopólio no uso da força legítima. Seu crescente poder como Estado absoluto, a utilização do Direito como intrumentum regni, exigirão como antítese, para garantir ao indivíduo um espaço pessoal, a reclamação de uns direitos. Mas, o Estado absoluto é uma etapa imprescindível. Seu esforço de centralização, de robustecimento de uma soberania unitária e indivisível, sua consideração do indivíduo abstrato, o homo juridicus como destinatário das normas, criará as condições necessárias para o aparecimento dos direitos fundamentais positivados exatamente com as revoluções liberais contrárias ao Estado absoluto.

Com efeito, desenvolvida no campo da filosofia no trânsito para a modernidade, é que a noção de dignidade humana vai se constituir como ideia motriz da construção da filosofia dos direitos fundamentais. Cabe salientar que, no entanto, em sua origem, a noção de dignidade humana 
não é uma noção jurídica, mas sim filosófica, que acaba por adentrar no campo do direito.

Peces-Barba (2005, p. 27) afirma que:

En su origen, dignidad humana no es un concepto jurídico como puede serlo el derecho subjetivo, el deber jurídico o el delito, ni tampoco político como Democracia o Parlamento, sino más bien una construcción de la Filosofia para expresar el valor intrínseco de la persona derivado de una serie de rasgos de identificación que la hacen única e irrepetible, que es el centro del mundo y que está centrada en el mundo. La persona es un fin que ella misma decide sometiéndose a la regla, que no tiene precio y que no puede ser utilizada como medio, por todas las posibilidades que encierra su condición, que suponen esa idea de dignidad humana en el punto de partida. Estamos ante un deber ser fundante que explica los fines de la ética pública política y jurídica, al servicio de ese deber ser. Por eso, la dignidad no es um rasgo o una cualidad de la persona que genera principios y derechos, sino un proyecto que debe realizarse y conquistarse.

Portanto, a ideia de dignidade humana como atributo de todos os seres humanos, centrada no "valor absoluto" de cada indivíduo do gênero humano, é uma construção social e histórica surgida no trânsito para a modernidade, distinguindo-se radicalmente do sentido que se dava à dignidade nas sociedades antigas e medievais, estando atrelada ao campo da filosofia moral e, posteriormente, aparecendo no campo da filosofia jurídica.

Entende-se que, muito embora inspiradora de toda a construção moderna da filosofia dos direitos fundamentais, a ideia de dignidade humana, no entanto, só adentra definitivamente no campo propriamente jurídico por meio da pressão social exercida pelo movimento social dos trabalhadores. Com efeito, de acordo com o que estipula Peter Häberle (2005, p. 117118), foi o movimento trabalhista que, definitivamente, se inspirando nas especulações filosóficas sobre a dignidade humana, construiu a ponte entre estas e a prática jurídica concreta. Afirma o autor alemão (HÄBERLE, 2005, p. 118, grifos nossos) com relação aos autores do século XIX: 
Na metade do século XIX a dignidade humana se tornou "idéia-motriz política do movimento trabalhista": Lassalle exige a melhoria das condições materiais das classes trabalhadoras e que se lhes proporcione uma existência verdadeiramente digna; Proudhon dá um passo adiante, ao incluir a dignidade da pessoa na idéia de justiça. Com isso, o pensamento da dignidade humana abriu-se a uma nova dimensão, a do Direito e da justiça, transitando do reino do "pensamento puro" para a prática jurídica.

Assim, a noção de dignidade humana, inspiradora da construção de toda a filosofia dos direitos fundamentais, ideal da burguesia em sua fase revolucionária diante das formas sociais do medievo, ou melhor do início da modernidade, tornou-se bandeira de luta do movimento social dos trabalhadores e adentrou no campo da prática jurídica como postulação concreta de melhores e dignas condições de trabalho, muito embora o seu evolver no campo do direito não tenha ficado restrito às relações de trabalho subordinado.

No processo de seu desenvolvimento prático e teórico no campo do direito, o valor/princípio da dignidade humana se espraiou de forma intensa por, praticamente, todos os campos do direito, destacando-se o campo dos direitos humanos proclamados em âmbito internacional, como é o caso, exemplar, da Declaração Universal dos Direitos Humanos de 1948, bem como adentrou nos ordenamentos jurídicos de vários países, como é o caso do Brasil com a Constituição Federal de 1988.

\section{A Noção de Dignidade Humana no Campo Jurídico, sua Positivação no Direito}

Como já foi mencionado, a ideia de dignidade humana foi desenvolvida no campo da filosofia moral e só posteriormente adentrou no mundo jurídico. No campo da filosofia, pode-se afirmar que foi Immanuel Kant quem formulou uma noção de dignidade humana que serve de fundamento da noção jurídica hoje dominante.

Para Kant, a ideia de dignidade está ligada ao homem como ser racional que, por sua vontade, obedece às leis que ele próprio institui. Se- 
gundo Kant, a moralidade consiste na legislação que possibilita o reino dos fins. Assim, ela (legislação) deve se encontrar em todo ser racional e deve prover de sua vontade, segundo o princípio que impõe que se deve "agir somente segundo uma máxima tal que possa ser erigida como lei universal”. Quanto à ideia de dignidade mesma, Kant (1984, p. 134-135) afirma:

No reino dos fins tudo tem um preço ou uma dignidade. Uma coisa que tem um preço pode ser substituída por qualquer outra coisa equivalente; pelo contrário, o que está acima de todo preço e, por conseguinte, o que não admite equivalente, é o que tem uma dignidade. Tudo o que se refere às inclinações e necessidades gerais do homem tem um preço de mercadoria; o que, embora não pressuponha uma necessidade, é conforme a um certo gosto, isto é, à satisfação que nos advém de um simples jogo, mesmo destituído de finalidade, de nossas faculdades intelectuais, tem um preço de sentimento; mas o que constitui a só condição capaz de fazer que alguma coisa seja um fim em si, isso não tem apenas simples valor relativo, isto é, um preço, mas sim um valor intrínseco, uma dignidade. Ora, a moralidade é a única condição capaz de fazer um ser racional ser um fim em si, pois só mediante ela é possível ser um membro legislador no reino dos fins. Pelo que, a moralidade, bem como a humanidade, enquanto capaz de moralidade, são as únicas coisas que possuem dignidade.

Em especial, a partir da construção kantiana, a doutrina jurídica lapidou a noção de dignidade humana, erigindo-a em valor central na construção da teoria dos direitos humanos e fundamentais (PÉREZ LUÑO, 2003, p. 572-573) ${ }^{5}$, além de princípio fundamental dos ordenamentos jurídicos hodiernos.

Com perceptível influência da posição kantiana, um dos autores que se debruçou sobre a ideia de dignidade humana no campo jurídico foi Günther Dürig. O referido autor desenvolveu a chamada "fórmula

\footnotetext{
${ }^{5}$ Antonio Enrique Pérez Luño (2003, p. 572-573) afirma que a "[...] condición axiológica de los derechos humanos no se agota en su dependência del concepto general de justicia, se prolonga en la determinación de su contenido ligado a los valores de la dignidad, la libertad y la igualdad".
} 
objeto", que acabou por ser encampada e consagrada pela Corte Constitucional Alemã. Segundo essa fórmula, sempre que uma pessoa humana for tratada como mero objeto (coisificação da pessoa humana) ou, ainda, sendo totalmente desprezada ou desconsiderada, ignorando-se suas necessidades básicas (nadificação da pessoa humana), sua dignidade humana estaria sendo ferida ${ }^{6}$.

Por seu turno, Eusebio Fernández García (2001, p. 12 e 17)7 , o qual utiliza os termos valor e princípio como intercambiáveis, aduz que a noção dignidade humana se apresenta como o valor de cada pessoa, do respeito básico à sua condição humana, impedindo que sua vida, ou integridade, seja substituída por qualquer outro valor social. O autor sustenta que a dignidade é o valor fonte de outros valores, como a autonomia, a segurança, a liberdade e a igualdade, os quais fundamentam os distintos tipos de direitos humanos. Então, sustenta Fernández García (2001, p. 19-20):

Cuando Kant, en la Fundamentación de la metafísica de las costumbres, mantiene que "lo que halla por encima de todo precio, $\mathrm{y}$ por tanto no admite nada equivalente, tiene una dignidade" y que "La autonomia es, así, pues, el fundamento de la dignidade de la naturaleza humana y de toda naturaleza racional", estaba reforzando ese enlace dignidad-derechos, puesto que la autonomía de los seres humanos significa la expresión de su mayoría de edad. Desde este momento histórico que es también el de las Declaraciones de derechos americana y francesas del útlimo cuarto del siglo XVIII, hasta la actualidad, se interpretará, creo que corretamente, la dignidade humana no solamente como lo más valioso, lo que no tiene precio, lo que exige un respeto inmediato, sino también como el derecho a tener derechos.

Por tanto, respetar la dignidade de los seres humanos equivale a reconocerles ciertos derechos. Si el reconocimento de los derechos humanos es el médio de garantizar la realización de una vida digna, su falta de recononocimiento significa vivir por debajo de la exigencia de esa viga digna.

\footnotetext{
${ }^{6}$ Sobre este assunto, ver Gonçalves (2010, p. 452).

${ }^{7}$ Em sentido contrário ao sustentado, Ana Paula Costa Barbosa (2002, p. 95) argumenta que o princípio da dignidade humana se funda nos valores da liberdade e da igualdade.
} 
Em linha semelhante está a posição de Peces-Barba, que sustenta que a dignidade humana é, hodiernamente, um referente do pensamento moral, político e jurídico, não propriamente como princípio ou valor, como aponta Eusebio Fernandez, mas como critério fundante dos valores, dos princípios e dos direitos ${ }^{8}$. Peces-Barba afirma (2005, p. 25) que:

La dignidad humana en la modernidad y también en este siglo XXI aparece en un contexto intelectual que arranca del tránsito a la modernidad, que ha superado avatares históricos y confrontaciones intelectuales y que se sitúa en lo que llamo el proceso de humanización y de racionalización que acompañan a la persona y a la sociedad en los diversos procesos de liberación, que conducen a la primera a la mayoría de edad y a la segunda a una organización bien ordenada que contribuye al desarrollo de las dimensiones de esa dignidad. La dignidad de la persona y la dignidad de la humanidad son dos aspectos de una misma mentalidad, la del antropocentrismo y de la laicidad, dos coordenadas que encuadran todo el proceso.

Antonio Luiz Martínez-Pujalte (1992, p. 91) alega que o que diferencia os seres humanos dos demais seres não humanos, momento em que, então, está radicada a dignidade humana, é a capacidade de entender e de querer, e, como consequência, a capacidade de conhecer a moralidade dos atos e atuar de acordo. Em suma, a dignidade humana tem sua raiz na potencialidade que o ser humano tem de ser autoconsciente e livre. Sendo assim, com base em Kant e Conklin, o autor Martínez-Pujalte (1992, p. 92-93) afirma que:

La dignidade humana se identifica con la condición de persona, como pone de relieve Kant, quien utiliza precisamente los térmi-

${ }^{8}$ Sobre essa diferença de pensamento em relação a Peces-Barba, por seu turno, afirma Fernández García (2001, p. 20): "Creo que no me sitúo lejos de Gregorio PECES-BARBA, cuando ha indicado, sobre la conexión entre la dignidade humana y los valores superiores de nuestro ordenamento jurídico constitucional (art. 1.1 de la C.E.), que "la dignidade humana es el fundamento y la razón de la necesidad de esos valores superiores, es la raíz última de todo, y creo que su inclusión entre los valores superiores no es metodologicamente correcta, puesto que estós son los caminhos para ser real y efectiva la dignidade humana". 
nos "dignidade" (Würde) y "personalidade" (Persönlichkeit) como sinónimos. Por su parte, el profesor canadiense William Conklin, tratando de indagar el sentido da la expresión "respeto a la persona" que subyace a la teoría de los derechos humanos, escribe que "la humanidade común a todas las personas es su potencialidade", pues "cada persona es una potencialidad aberta en el processo de llegar a ser.

Ingo Wolfgang Sarlet (2012, p. 49-73), seguindo os passos de Kant e Dürig, defende que a dignidade humana é uma qualidade ínsita a cada pessoa humana e que a distingue dos demais seres, razão pela qual todo indivíduo é merecedor de igual respeito e consideração por parte de todos. Sarlet (2012, p. 73) assim define a dignidade da pessoa humana:

Assim sendo, temos por dignidade da pessoa humana a qualidade intrínseca e distintiva de cada ser humano que o faz merecedor do mesmo respeito e consideração por parte do Estado e da comunidade, implicando, neste sentido, um complexo de direitos e deveres fundamentais que assegurem a pessoa tanto contra todo e qualquer ato de cunho degradante e desumano, como venham a lhe garantir as condições existenciais mínimas para uma vida saudável, além de propiciar e promover sua participação ativa e corresponsável nos destinos da própria existência e da vida em comunhão com os demais seres humanos.

Da mesma forma, outro autor brasileiro que trata com maestria a questão da dignidade da pessoa humana, Daniel Sarmento (2016, p. 104, grifos do autor), leciona que:

No Direito contemporâneo a palavra 'dignidade' tem sido usada [...] geralmente associado aos direitos humanos. A palavra dignidade é empregada como qualidade intrínseca de todos os seres humanos, independentemente de seu status e de sua conduta. A dignidade é ontológica, e não contingente. Em outras palavras, todos os indivíduos que pertencem à espécie humana possuem dignidade apenas por serem pessoas. 
E também destaca Daniel Sarmento (2016, p. 104), no sentido da igualdade existente na questão da dignidade da pessoa humana, que:

Não se admitem restrições relativas a fatores de gênero, idade, cor, orientação sexual, nacionalidade, deficiência, capacidade intelectual ou qualquer outro. E ninguém se despe de dignidade humana, ainda que cometa crimes gravíssimos, que pratique os atos mais abomináveis. O homicida e o torturador têm o mesmo valor intrínseco que o herói e que o santo. A dignidade humana, que não é concedida por ninguém, não pode ser retirada pelo Estado ou pela sociedade, em nenhuma situação. Ela é inerente à personalidade humana e, portanto, embora possa ser violada e ofendida pela ação do Estado ou de particulares, jamais será perdida pelo seu titular.

Por sua vez, Maria Rosynete Oliveira de Lima (1999, p. 213), partindo do disposto no artigo $1^{\circ}$ da Declaração Universal dos Direitos do Homem de 1948 ("Todos os seres humanos nascem livres e iguais em dignidade e em direitos. Dotados de razão e de consciência devem agir uns para com os outros em espírito de fraternidade"), fala sobre os postulados básicos para que se estabeleça o que significa a dignidade da pessoa humana. Por sua vez, o constitucionalista português da Universidade de Lisboa, Jorge Miranda, ressalta os postulados fundamentais e as projeções da dignidade da pessoa humana:

a) A dignidade da pessoa humana reporta-se a todas e a cada uma das pessoas e é a dignidade da pessoa individual e concreta; b) Cada pessoa vive em relação comunitária, mas a dignidade que possui é dela mesma, e não da situação em si; c) O primado da pessoa é o ser, não o ter; a liberdade prevalece sobre a propriedade; d) Só a dignidade justifica a procura da qualidade de vida; e) A proteção da dignidade das pessoas está para além da cidadania portuguesa e postula uma visão universalista da atribuição de direitos; f) A dignidade da pessoa pressupõe a autonomia vital da pessoa, a sua autodeterminação relativamente ao Estado, às demais entidades públicas e às outras pessoas; [...] h) A dignidade da pessoa exige condições adequadas de vida material; i) $O$ primado da pessoa é o ser, não o ter prevalece sobre a propriedade; j) Só a dignidade justifica a procura da qualidade de vida; 1) A dignidade de 
cada pessoa é um prius em relação à vontade popular. (MIRANDA, 2004, p. 199-200, grifos nossos)

Assim, pode-se dizer que a dignidade da pessoa humana é uma categoria axiológica aberta a ser preenchida/completada pelo intérprete da norma no momento de sua concretização. Portanto, segundo Marya Rosynete Lima (1999, p. 214) “[...] é preciso levar em conta as exigências básicas do ser humano em concreto, indispensáveis para dar-lhe uma existência digna, bem como para proporcionar-lhe as condições de desenvolvimento das suas potencialidades".

Levando em conta todas essas contribuições da doutrina sobre o valor/princípio ${ }^{9}$ da dignidade da pessoa humana, é possível tentar delinear algumas das consequências prático-jurídicas de sua previsão no ordenamento jurídico constitucional brasileiro. A dignidade é destacada praticamente em todas as declarações e tratados internacionais sobre direitos humanos e está consagrada em pelo menos 149 constituições vigentes em suas respectivas nações (SARMENTO, 2016, p. 15), ainda que a questão de sua efetividade seja outro assunto bastante mais complexo ${ }^{10}$.

No direito brasileiro vigente, a noção de dignidade humana é prevista como princípio fundamental constitucional no inciso III do artigo $1^{\circ}$ da CF de 1988, configurando-se como uma das chaves de interpretação de todo o ordenamento jurídico vigente ${ }^{11}$. Com efeito, todo o ordenamento jurídico brasileiro deve ser interpretado a partir dos princípios fundamentais de "abrem a ordem jurídica nacional", os quais estão previstos no

\footnotetext{
${ }^{9}$ No presente texto, os vocábulos “valor" e "princípio" são tomados como intercambiáveis. 10 Entre os 149 países que expressamente consagram a dignidade estão incluídos verdadeiras ditaduras e regimes de exceção em que não há igualdade, liberdade e justiça imparcial. A hipocrisia é uma terrível característica humana e em muitos países usam a dignidade humana apenas como demagogia. Assim, é possível encontrar a consagração da dignidade humana em países notórios pelas graves violação dos direitos humanos, como a Síria de Al Bashar, o Sudão e a Somália, entre muitos outros em todo o mundo (entre os quais seria possível citar diversos países da América Latina, até mesmo o Brasil pela situação de extrema pobreza de boa parte de sua população).

${ }^{11}$ Sobre o tema, entre outros, ver Gomes (1996) e Oliveira (2002) e Oliveira (2002).
} 
primeiro Título da CF de 1988, entre os quais, o princípio da dignidade da pessoa humana tem caráter destacado ${ }^{12}$.

Está previsto ainda, no artigo 170, caput, da CF de 1988, como um princípio impositivo da ordem econômica, ou seja, princípio a ser observado pela atividade econômica, ao determinar que toda a atividade econômica tem como fim garantir "vida digna"13.

Além disso, o princípio da dignidade da pessoa humana é a fonte primordial dos direitos humanos fundamentais, estabelecendo também o limite absoluto das restrições a esses direitos (núcleo essencial em dignidade), pois é indisponível. Além disso, se irradia por toda a sociedade, ou seja, esse princípio atua não apenas nas relações entre Estado e indivíduo, mas nas relações interindividuais também.

A consagração constituída do princípio da dignidade da pessoa humana traduz-se no reconhecimento de que a ordem jurídica existe para a pessoa humana, sua defesa e para o desenvolvimento integral. Assim, caracteriza-se como princípio que serve de base sólida para a construção de um sistema jurídico que aspire a um mínimo de legitimidade ${ }^{14}$.

O princípio da dignidade da pessoa humana estabelece um grau de proteção e autonomia da pessoa humana frente ao Estado e às demais pessoas humanas ou pessoas jurídicas públicas ou privadas, além de impor a satisfação de condições mínimas de existência capazes de fazer com que o ser humano consiga realmente viver e não apenas sobreviver. Na verdade, não é possível descrever todas as esferas e consequências que podem advir de sua previsão no direito positivo, pois sua normatividade se expande de acordo com os contextos sociais ao longo do tempo.

\footnotetext{
12 Robert Alexy (2008) distingue diante da "norma" que prevê a dignidade humana, a "regra" de dignidade e o "princípio" da dignidade. A regra de dignidade, uma vez definida sua aplicação, é impostergável. Por outro lado, muito embora entenda possível o sopesamento do princípio da dignidade humana frente a outros princípios constitucionais, Alexy (2008, p. 114) afirma que existe um âmbito praticamente inafastável da dignidade humana, ou seja, que o princípio da dignidade humana se encontra num patamar diferenciado frente aos demais princípios.

${ }^{13}$ Ver, nesse sentido, Grau (2002. p. 238 e ss.).

${ }^{14}$ Ver sobre esse tema em Tepedino (2001, p. 67).
} 
Dessa forma, o princípio da dignidade da pessoa humana coloca em foco o tema do chamado "mínimo existencial”. Na lição de Ricardo Luís Lorenzetti (1998, p. 328), com base em Rawls, o mínimo existencial se caracteriza como os bens fundamentais que são descobertos pela indagação de quais condições sociais são necessárias para tornar possível que as pessoas realizem sua ideia do bem e desenvolvam e exerçam suas capacidades morais. Esses bens, continua o autor, são aqueles de que o indivíduo necessita para conseguir desenvolver-se minimamente na sociedade, abrangendo liberdade, trabalho, moradia, educação, saúde. Portanto, são bens que correspondem à própria qualidade humana, cabendo ao direito e à organização social e econômica, que devem servir aos homens, garantir esses bens para que se possa realmente falar em pessoa humana. Em virtude disso, tais bens fundamentais são um mínimo social, uma base que corresponde ao bom funcionamento da organização humana e que permite a ela continuar sendo chamada dessa maneira.

Portanto, existe a tendência de construção de um piso mínimo de direitos básicos, fundamentais; assim, esses direitos subjetivos são oponíveis aos sujeitos passivos, que tanto podem ser o Estado como os demais cidadãos. Cabe salientar, ainda, que a autonomia da pessoa humana, da qual se fala, não deve ser entendida em sentido individualista, mas sim como individualidade que coexiste com outras individualidades, uma pessoa humana autônoma, mas não isolada, integrante de uma sociedade que está em relação com outras pessoas.

Aliás, nesse sentido, afirma Luiz Fernando Barzotto (2010, p. 4546) $)^{15}$ :

Desse modo, a pessoa está para a natureza humana como o todo para a parte. A pessoa é o homem singular e concreto, portanto, a natureza humana (racionalidade, sociabilidade, etc.), com seus acidentes (idade, inteligência, etc.), unidos existencialmente. "Humano" designa uma classe ou um gênero, um grupo, a espécie. Pessoa

\footnotetext{
${ }^{15}$ Para uma concepção de dignidade humana intimamente vinculada com considerações sobre a solidariedade social, a qual é necessária para que o indivíduo possa se realizar na organização social em colaboração efetiva com os demais, no cuidado mútuo e, assim, em posição diametralmente oposta ao individualismo, ver Ramose (2010, p. 175-220).
} 
designa "algum homem" e, portanto, um existente. [...] Ao passo que o elemento individualidade, existência em si, aplicada à pessoa, seja intuitivo, o segundo elemento da ideia de pessoa, a alteridade, é insólita, por sua oposição ao individualismo moderno. Contudo, a ideia de alteridade, ou o caráter relacional do ser humano é central .... A pessoa é um ser em relação ou um ser com outrem ... Isso significa que não há pessoa anteriormente à relação com outra pessoa: "A experiência do outro é tão originária quanto a experiência de si”. Não há uma percepção de si como pessoa e, posteriormente, a percepção do outro como pessoa. Somente na relação alguém é pessoa.

Outra questão, que não parece demasiado distinguir e salientar, é que a dignidade da pessoa humana se aplica ao indivíduo humano, às "pessoas físicas/naturais", não sendo estendível às "pessoas jurídicas" públicas ou privadas, situação que muitas vezes parece não ficar muito clara. Um exemplo importante dessa temática é a atribuição, sem maiores reflexões, de direitos fundamentais às pessoas jurídicas.

Com efeito, José Carlos Vieira de Andrade (2001, p. 183) é enfático em defender um cuidado extremo na atribuição de direitos fundamentais às pessoas jurídicas. $\mathrm{O}$ autor adverte que é perigoso estender demasiadamente os direitos humanos fundamentais às pessoas coletivas, pois essas pessoas apenas analogicamente podem ser consideradas titulares desses direitos como direitos atípicos. Afirma ainda que, nesses casos, não se trataria de verdadeiros direitos subjetivos, mas de garantias institucionais, já que os direitos humanos fundamentais têm como verdadeiro titular a pessoa humana.

No mesmo sentido, no campo da filosofia crítica, Franz Hinkelammert (2012, p. 105-107) sustenta que os direitos humanos estão fundados na dignidade da pessoa humana, o que só cabe às "pessoas naturais", não às "pessoas jurídicas". O autor afirma que:

Si hoy tenemos que decidir sobre instituciones a partir de los derechos humanos, tenemos que tener claro que las instituciones no tienen derechos humanos, sino que están sometidas al criterio de los derechos humanos [...]. 
Sin embargo, el derecho humano consiste en derechos que corresponden al ser humano como ser corporal integral y que incluye el derecho de vivir. Expresado en el lenguaje jurídico, se trata de derechos de personas naturales, a diferencia de las personas jurídicas. Las personas jurídicas no tienen derechos humanos, porque no son seres humanos, solamente las personas naturales los tienen. Las grandes sociedades anónimas son personas jurídicas, como tales no pueden tener ninguna clase de derechos humanos. Las personas jurídicas no tienen derechos humanos, solamente las personas naturales los tienen. (HINKELAMMERT, 2012, p. 105-107)

Robert Alexy (2003, p. 25-26) também tem posição semelhante, ao afirmar que os direitos fundamentais são essencialmente direitos dos "indivíduos" e sempre que se admite a sua extensão a grupos, organizações ou pessoas jurídicas, é porque tal reconhecimento favorece a posição de indivíduos.

Assim, entende-se que, tendo por baliza o princípio da dignidade da pessoa humana, é possível avaliar, com o adequado "espírito crítico", até que ponto cada sociedade (aqui envolvendo o Estado e a chamada "sociedade civil"), num determinado momento histórico, realmente está tratando a cada pessoa humana, a cada indivíduo socia ${ }^{16}$ como um fim e não como um meio; como um sujeito dotado de eticidade que põe e julga os fins ${ }^{17}$; até que ponto suas necessidades ${ }^{18}$ estão sendo satisfeitas ou inviabilizadas pela

\footnotetext{
${ }^{16}$ Como bem lembra Karl Marx (2008a, p. 74, nota 18), a pessoa humana só se vê e se reconhece em seu semelhante. Além disso, com finesse crítica, Marx (2008b, p. 239) afirma: "O homem, no sentido mais literal, é um zoon politikon (animal político - grego - N.E.), não somente um animal sociável, mas também um animal que não se pode isolar senão dentro da sociedade".

${ }^{17}$ Sobre tal temática, afirma Enrique Dussel (2002, p. 491, nota 358): “[...] Como afirmaba Kant, la persona no es un medio; pero, más allá de Kant, no es tampoco un fin, sino que es un sujeto ético que 'pone' (y 'juzga') los fines"”.

${ }^{18}$ Não se deve perder de vista que as "necessidades" não são apenas físicas, orgânicas, mas também sociais, históricas, culturais. Sobre esse tema, ver Marx (2011, p. 222) e Marx (2008a, p. 57, 64 e 201). Da mesma forma sobre necessidades humanas básicas e mínimo existencial, ver Sarmento (2016, p. 189-239), especificamente o Cap. 5: O mínimo existencial, e Añón Roig (1994).
} 
estrutura social; até que ponto lhe é possível viver como humano que possa aspirar ao desenvolvimento integral de sua humanidade.

\section{Reflexos Prático-Jurídicos do Princípio da Dignidade da Pes- soa Humana no Campo Laboral}

No campo das relações de trabalho, o princípio da dignidade da pessoa humana tem um espectro de possibilidades de aplicação extremamente vasto. Cabe lembrar que o princípio basilar do direito do trabalho é o princípio da proteção ${ }^{19}$.

O princípio da proteção, nuclear no direito do trabalho, tem como propósito diminuir a desigualdade material entre patrões e empregados por meio de compensações jurídicas. Assim, o princípio da proteção impõe a busca pela efetivação, nos limites do modo de produção dominante, de uma igualdade substancial entre partes de uma relação estrutural e contratualmente desigual.

O princípio da proteção é fundamental para a própria existência do direito do trabalho, pois esse ramo do direito surge justamente das diferenças de poder socioeconômico entre empregadores e empregados.

Pois bem, o princípio da proteção é a materialização, a projeção, a concretização no campo das relações de trabalho subordinado, do princípio da dignidade da pessoa humana. Isso não significa que o princípio da dignidade humana não tenha projeção direta nas relações de trabalho, mas, sim, que ganha densidade normativa com a atuação do princípio da proteção, o qual, por outro lado, ganha um alto grau de legitimidade ético-jurídica ao estar fundado na dignidade humana.

Cinthia Maria da Fonseca Espada (2008, p. 96), em sentido semelhante ao já sustentado, aponta que:

Com base nesta definição pode-se afirmar que a incidência do princípio da dignidade da pessoa humana no âmbito do trabalho impli-

${ }^{19}$ Sobre essa questão, ver Rodrigues (1978, p. 27), Genro (1994), Camino (2003, p. 9697), Delgado (2008, p. 197 e ss.), Delgado e Delgado (2017, p. 69 e ss.). 
ca a necessidade de se proteger o trabalhador contra qualquer ato atentatório à sua dignidade, de lhe garantir condições de labor saudáveis e dignas, e também de propiciar e promover a inclusão social. Constata-se, desta forma, que o núcleo do princípio protetor do empregado encontra seu fundamento no princípio da dignidade da pessoa humana, considerando-se que a principal finalidade da proteção ao trabalhador é promover a sua dignidade. Nesse passo, embora o propósito do princípio protetor do empregado também seja o de tratar desigualmente os desiguais para promover a igualdade real/substancial entre partes que se encontram em desigualdade de fato (princípio isonômico) em seu núcleo, a principal finalidade do princípio é promover a dignidade do trabalhador. Assim, promover a igualdade real constitui um dos meios de promoção da dignidade do obreiro.

Häberle (2005, p. 113), por seu turno, analisando a jurisprudência dos Tribunais alemães sobre a dignidade humana nas relações de trabalho, afirma que:

A jurisprudência federal trabalhista prevalentemente trata de modo mais específico a irradiação do art. $1^{\circ}$. da LF sobre as relações de emprego. Na verdade, trata-se aqui da proteção da esfera íntima e privada no sentido do direito geral de personalidade, embora fique, apesar disso, em primeiro plano uma configuração humanamente digna da relação de emprego, na qual também o empregador encontra-se obrigado por um dever de cuidado e assistência (Fürsorgepflicht). Trata-se como que de um direito da personalidade específico da esfera trabalhista. A configuração dessa relação de emprego, bem como o direito coletivo do trabalho, encontra seus limites no art. $1^{\circ}$. da LF; ainda na negação de uma violação da dignidade humana à luz da vinculação comunitária do cidadão repousa também uma determinação de conteúdo específica do direito do trabalho.

Dito isso, conforme já salientado, percebe-se que as possibilidades de incidência do princípio da dignidade humana no campo do direito do trabalho são bastante amplas. 
No campo do direito internacional, entre inúmeras outras Declarações e Convenções Internacionais, cabe destacar a Declaração da OIT sobre os Princípios e Direitos Fundamentais no Trabalho de $1998^{20}$, a qual tem por pressuposto o princípio da dignidade humana. Tal declaração proclama quatro direitos fundamentais básicos dos trabalhadores: a) a liberdade sindical e o reconhecimento efetivo do direito de negociação coletiva; b) a eliminação de todas as formas de trabalho forçado ou obrigatório; c) a abolição efetiva do trabalho infantil; e d) a eliminação da discriminação em matéria de emprego e ocupação. A íntima vinculação de tais direitos com a dignidade humana é solar.

A liberdade sindical e o reconhecimento das negociações coletivas têm a função de garantir um patamar de maior força e equilíbrio aos trabalhadores nas suas tratativas, compensando sua debilidade individual, ficando evidenciado o objetivo de proteção à dignidade dos trabalhadores, reconhecendo e reforçando a sua autonomia por meio dos entes coletivos obreiros.

Com relação à eliminação do trabalho forçado ou obrigatório, o vínculo com o princípio da dignidade humana é ainda mais evidente, pois essas formas de trabalho coisificam o ser humano, degradando a sua condição de pessoa e reduzindo as vítimas, absolutamente, à condição de coisas, de objetos.

Outrossim, a vinculação da eliminação do trabalho infantil com a dignidade humana também é evidente, pois o trabalho infantil agride frontalmente a possibilidade do livre desenvolvimento da personalidade de crianças e adolescentes que, ainda em fase de amadurecimento, são cerceados em suas possibilidades de um desenvolvimento amplo de suas capacidades e potencialidades.

Por fim, no tocante à eliminação de todas as formas de discriminação, além do vínculo efetivo com o princípio da igualdade, a vinculação com o princípio da dignidade humana é também bastante forte, pois aqui

${ }^{20}$ A referida Declaração da OIT está disponível neste endereço eletrônico: https://www. ilo.org/public/english/standards/declaration/declaration_portuguese.pdf. 
se trata de garantir o igual respeito e consideração que toda pessoa humana deve ter garantida em razão de integrar o gênero humano.

Outro tema de extrema relevância, o qual tem também estreita vinculação com o princípio da dignidade humana no campo das relações de trabalho subordinado, é o relativo à chamada "eficácia horizontal ou eficácia dos direitos fundamentais em relações privadas".

Sobre o tema da vinculação dos particulares à dignidade humana, Sarlet (2012, p. 99) afirma o seguinte:

Para além desta vinculação (na dimensão positiva e negativa) do Estado, também a ordem comunitária e, portanto, todas as entidades privadas e os particulares encontram-se diretamente vinculados pelo princípio da dignidade da pessoa humana. Com efeito, por sua natureza igualitária e por exprimir a ideia de solidariedade entre os membros da comunidade humana, o princípio da dignidade da pessoa humana vincula também no âmbito das relações entre os particulares.

Nessa temática, duas ideias básicas são primordiais para a defesa da incidência dos direitos fundamentais nas relações privadas: a existência de relações assimétricas (de poder no âmbito privado) e o princípio da dignidade humana. Esse último é um forte componente para que se intensifique a incidência desses direitos nas relações privadas em geral e nas relações de trabalho subordinado, em especial ${ }^{21}$.

Além de inúmeras outras possibilidades, são exemplos concretos de aplicação jurisprudencial do princípio da dignidade da pessoa humana no campo do direito do trabalho, a proteção contra o trabalho escravo (Inq. n. 3.412, Plenário do STF, disponível em: www.stf.jus.br); a vedação do assédio moral (RR-890-89.2013.5.09.0653, 6 $6^{\text {a }}$ Turma do TST, disponível em: www.tst.jus.br); a vedação do assédio sexual (RO 002208283.2015.5.04.0221, $7^{\text {a }}$ Turma do TRT4, disponível em: www.trt4.jus.br); e a indenização do chamado "dano existencial". ${ }^{22}$

${ }^{21}$ Ver, nesse sentido, Bilbao Ubillos (2010, p. 284).

${ }^{22}$ Ver, nesse sentido, a decisão proferida pela $1^{\mathrm{a}}$ Turma do TRT da $4^{\mathrm{a}}$ Região, em 14.03.2012, no processo 0000105-14.2011.5.04.0241 (o qual pode ser conferido no site do Tribunal - 
Portanto, é evidente a projeção do princípio da dignidade humana no campo das relações de emprego, o que é fundado não apenas na doutrina, como também na jurisprudência.

Além disso, não há o que contestar sobre a importância central da incidência do princípio da dignidade humana para a efetividade da proteção dos trabalhadores no âmbito laboral.

No entanto, não se pode esquecer de uma pergunta que, ao que se entende, não é comumente feita, e que tanto deveria interessar: a dignidade humana, ou seja, o ser humano ser tratado como fim e não como meio é amplamente possível numa relação na qual o indivíduo passa a ser meio de produção subordinado/dependente a uma estrutura socioeconômica que não lhe pertence?

Eis a questão que será tratada em seguida.

\section{Os Limites Estruturais para a Plena Incidência da Dignidade Humana nas Relações de Trabalho Subordinadas}

Conforme foi abordado no presente texto, a ideia de dignidade humana, profundamente marcada pelo pensamento kantiano, pode ser sintetizada como a qualidade que é reconhecida a cada ser humano, apenas pelo fato de pertencer ao gênero humano, de ser tratado e considerado

\footnotetext{
ww.trt4.jus.br), tendo como relator o des. fed. do trabalho José Felipe Ledur, com a seguinte ementa: Dano existencial. Jornada extra excedente do limite legal de tolerância. Direitos fundamentais. "O dano existencial é uma espécie de dano imaterial, mediante o qual, no caso das relações de trabalho, o trabalhador sofre danos/limitações em relação à sua vida fora do ambiente de trabalho em razão de condutas ilicitas praticadas pelo tomador do trabalho. Havendo a prestação habitual de trabalho em jornadas extras excedentes do limite legal relativo à quantidade de horas extras, resta configurado dano à existência, dada a violação de direitos fundamentais do trabalho que integram decisão jurídicoobjetiva adotada pela Constituição. Do princípio fundamental da dignidade da pessoa humana decorre o direito ao livre desenvolvimento da personalidade do trabalhador, nele integrado o direito ao desenvolvimento profissional, o que exige condições dignas de trabalho e observância dos direitos fundamentais também pelos empregadores (eficácia horizontal dos direitos fundamentais). Recurso provido".
} 
como um fim em si, o que deveria impedir a sua objetificação, coisificação, enfim, a sua degradação/desconsideração como indivíduo.

Ocorre que, em especial, nas relações de trabalho subordinado, a pessoa do trabalhador está inserida numa relação socioeconômica estrutural na qual está em posição de subordinação/depedência em relação ao outro polo dessa relação (o patrão/empregador).

Como a força de trabalho está em potência na própria corporalidade viva do trabalhador, não existe como comandar e adquirir essa força de trabalho desconectada da pessoa humana que a porta, ou seja, para poder utilizar a força de trabalho, inevitavelmente deve-se utilizar como meio a pessoa que o presta.

Eis um limite estrututal que o modo de produção dominante impõe para a ideia da dignidade humana.

Cumpre enfatizar, aliás, que a contradição existente entre o trabalho assalariado (no caso dos serviçais domésticos, trabalhadores assalariados) e a dignidade humana não passou despercebida para o próprio Kant, o que não significa que o autor não tenha se rendido e tentado justificar tal situação. Tanto é assim, que o autor criou uma categoria especial de direito, o chamado "ius realiter personale", no qual o trabalhador era, em parte, tratado como se fosse uma coisa, embora mantivesse, em outros aspectos, sua personalidade.

Com efeito, na "Seção III" da Doutrina do Direito, Kant (1993, p. 104) trata daquilo que denomina "direito misto" ou "direito real pessoal" (ius realiter personale). Segundo Kant, esse direito é o da posse de um objeto exterior como se fosse uma coisa, de seu uso como o uso de uma pessoa. Três tipos de relações são possíveis aqui: a "aquisição" pelo homem de uma mulher; a "aquisição" de filhos pelo casal e a "aquisição" pela família de servos. No entanto, Kant salienta que se essas coisas são passíveis de aquisição, não são de alienação, e o direito do possuidor é eminentemente pessoal. Tratando especificamente das relações que se dão entre o senhor e os servos (trabalhadores assalariados domésticos), relação que reconhece não ser de igualdade, mas de obediência, Kant (1993, p. 104) diz: 
Os servidores ou criados formam parte, neste estado de coisas, do Seu do amo da casa, ainda em virtude de direito real, pelo que respeita à forma (o estado de posse); porque o amo pode, caso seu criado fuja, fazê-lo retornar ao seu poder por sua única e própria vontade; porém quanto à matéria, isto é, quando ao uso, ao serviços que dele se possa obter, não poderá nunca exercer ato de proprietário (dominus servi), porque o servidor somente está submetido ao seu poder por um contrato, e um contrato no qual uma das partes renunciara a sua liberdade inteira em proveito alheio, cessando, por conseguinte, de ser uma pessoa, e não tendo, pelo mesmo, nenhum dever de observar o contrato, é uma contradição. Tal contrato é, pois, nulo e de nenhum efeito. Não nos compete aqui falar do direito de propriedade sobre o que perdeu sua personalidade por seus crimes. O contrato de um amo sobre a liberdade de um servidor não pode, portanto, ser de tal natureza que o que obriga possa fazer degenerar o uso da liberdade de outro em abuso. Não só o amo tem o direito de julgar com respeito a este uso, como também o criado. Este nunca pode ser reduzido à servidão. Não pode, portanto, comprometer-se por toda sua vida, mas somente por um tempo determinado; e durante este tempo uma das partes contratantes pode despedir a outra. $[$...]

Nisto, como nos dois títulos que precedem, vê-se que há um direito pessoal-real (o do amo sobre os criados), visto que estes podem ser reduzidos ao poder daquele e reivindicados como sua coisa exterior contra todo possuidor, mesmo antes que seja necessário examinar as razões que pudessem ter tido para fugir e o direito que lhes assista.

Celso Naoto Kashiura Jr. (2014, p. 72, 82-89) lembra que Kant está situado geográfica e historicamente no momento da transição das relações feudais de produção para relações propriamente capitalistas (burguesas). Na sua Prússia, então atrasada em relação à Inglaterra, por exemplo, ainda as relações capitalistas não estavam de todo consolidadas, muito embora o trabalho assalariado já se fizesse presente. Salienta, ainda, que as contradições do pensamento kantiano não são senão as contradições realmente existentes na realidade, cabendo a Kant, muito embora sua defesa do sistema, a intuição de ter percebido a desigualdade e as contradições 
inerentes às relações capitalistas burguesas. Kashiura Jr. (2014, p. 143144) menciona que:

Se, como propõe Tosel, o direito é, na formulação de Kant, como um centauro, o meio do caminho entre a pureza ideal da moralidade e a exterioridade empírica, o criado doméstico submetido ao ius realiter personale expressa com máxima evidência essa condição de ser híbrido. Meio coisa e meio homem, traz na sua cabeça a forma racional da liberdade, mas o seu corpo é o de uma besta. Kant procura, ao seu modo, elevá-lo à condição de sujeito livre, mas não pode negar a sua coisificação perante o senhor. Não pode dissimular, mesmo sob a forma da personalidade jurídica, a desigualdade de ambos $[\ldots]$.

A formulação kantiana tende, assim, a ratificar simultaneamente a circulação mercantil livre - na forma da universalidade dos livres proprietários, frente aos quais não pode haver res nullius - e elementos residuais de uma produção senhorial presa à terra - na forma de uma coisificação do trabalhador que perpetua explicitamente, embora de maneira atenuada, o mando do senhor.

Como sustenta Dussel (2002, p. 322), citando explicitamente Marx, nas relações de trabalho no modo de produção capitalista, ocorre uma inversão ética estrutural: o fim se torna meio e o meio se torna fim. Dussel (2002, p. 322) diz ainda que:

La "fuente creadora del valor" (persona digna y que pone los fines) queda fundada en su producto (como su mediación): se trata de una "inversión". La valorización del valor es el "ser" y el "fundamento" de un sistema que vive de la vida del obrero, es una ontología totalizada:

El proceso del trabajo se manifiesta en el interior de la produción capitalista con respecto al proceso de valorización, situando a este último como fin, y a sí mesmo [al trabajo] sólo como medio.

Marx se refiere explícitamente a Kant, la persona del trabajador es colocada como medio, y el medio (es proceso de valorización del capital), como fin. Es la inversión que se expresa en el fenómeno 
del fetichismo. [...] Esta inversión, esta negación ética primera, esencial para la reproducción del capital como tal, y en la que consiste la relación social de dominación, se cumple en el proceso de la "subsunción" [...].

Bernard Edelman (1976) é enfático ao afirmar a aporia da "forma sujeito", na qual se reconhece a uma pessoa humana a sua dignidade no exato momento em que a transforma em objeto. Se reconhece que os trabalhadores são sujeitos livres e iguais, juridicamente dotados de dignos para que possam livremente venderem-se no mercado. Com efeito, aponta Edelman (1976, p. 94):

A Forma sujeito de direito é aporética, isto é, põe um problema que não pode resolver. Se o homem é para ele mesmo o seu próprio capital, a circulação deste capital supõe que ele possa dispor dele em nome (ao preço) dele próprio, isto é, em nome do mesmo capital que o constitui. Podemos resumir esta aporia: o homem deve ser simultaneamente sujeito e objeto de direito. A estrutura da forma sujeito de direito analisa-se então como decomposição mercantil do homem em sujeito/atributos.

\section{Assim segue Edelman (1976, p. 105) em suas ideias acerca da Dou- trina:}

Quanto à "má consciência da Doutrina", posso situá-la no seu discurso latente, que enuncia a adequação "de direito natural" da pessoa humana e do sujeito de direito. A interpelação ideológica - toda a pessoa é sujeito de direito - tornando-se categoria eterna - o sujeito de direito é qualquer pessoa - mergulha a doutrina num terrível embaraço. Porque, se a Forma Sujeito é bem a forma necessário do homem que participa nas trocas e na produção, ela é além disso esta Forma na qual se deve também realizar a liberdade e a igualdade. E, para "eles", o dilema vem a ser o seguinte: o sujeito de direito realiza a sua liberdade pela venda dele próprio. Estes professores não compreenderam que a categoria de sujeito de direito é um produto da história, e que a evolução do processo capitalista realiza aí todas as determinações: o sujeito de direito torna-se o seu último produto: objecto de direito. 
Não se quer com isso afirmar a falta de importância do princípio da dignidade humana no campo laboral, assim como não se quer dizer que não exista a possibilidade de trabalhos e de tratamentos mais dignos ou menos dignos (basta pensar no trabalho precarizado, de crianças em tenra idade ou em situação análoga à de escravo). O que se quer é chamar a atenção para o limite que o modo de produção impõe ao direito, ao mesmo tempo em que se demonstra que a realização plena da dignidade humana teria que ultrapassar esse limite.

Como sustenta Juan Ramón Capella (1998, p. 82), o limite da socialização sob o capitalismo está no fato de que os indivíduos são postos, nesse sistema, como meios de valorização do capital, para que os investimentos se recuperem acrescidos de lucros que são apropriados privadamente. $\mathrm{O}$ autor afirma:

A socialização capitalista, a reunião em cooperação objetiva das pessoas, que suscita esse modo econômico de produção, cuja eficácia em abstrato é indiscutível, tem, pois, o limite de não dispor de mecanismos que façam das pessoas fins em si mesmos e entre si mesmos, que sejam invioláveis pelo processo de socialização da produção.

Conseqüência: para uma socialização pós-capitalista, onde isto não ocorra, é necessário diferenciar os mecanismos contáveis da racionalidade ou eficiência da cooperação produtiva - projetos e planos públicos, mercados de ajuste, etc. - dos mecanismos de decisão acerca da produção e de distribuição do produto (material e espiritual) sem os quais uma pessoa não pode ser considerada fim em si mesma. No capitalismo, os mecanismos e sujeitos sociais que controlam a eficiência econômica são os mesmos que decidem a produção e determinam a distribuição. Diferenciar ambas as questões é tarefa de formas de organização social efetivamente emancipatórias. (CAPELLA, 1998, p. 82)

Assim, para a uma realização mais efetiva da ideia de dignidade humana nas relações sociais em geral, e nas de trabalho, em especial, seria necessária a construção de outras formas de convívio social, possíveis e viáveis, nas quais as condições de produção e distribuição fossem pautadas 
pelo controle social dos indivíduos associados, bem como nas quais o valor de uso (riqueza material) prevaleça sobre o valor (riqueza capitalista).

No entanto, enquanto não se efetivam essas outras formas socias e, portanto, dentro dos limites impostos pela forma social capitalista, o princípio da dignidade humana possui uma carga normativa extremamente vigorosa, a qual não pode ficar como mera promessa do prevista nos textos normativos fundamentais, mas deve ser expressa e concretizada em cada manifestação jurídica.

\section{Conclusão}

Como se tentou evidenciar, a ideia de dignidade humana, muito embora tenha um longo percurso na história, só ganha o sentido que lhe é hodiernamente reconhecido no trânsito para a modernidade. Nesse momento histórico o labor, primeiramente dos filósofos e depois dos juristas, vai lapidar a noção moderna de dignidade. Um dos nomes-chave nesse processo é o de Kant, para o qual a dignidade, tendo em vista a racionalidade e a liberdade humanas, significa tratar o homem como um fim em si.

Adentrando no mundo jurídico positivo, em muito pela pressão social dos trabalhadores, a dignidade humana é alçada ao patamar de princípio (valor) central e fundamental, sendo a base sólida para a construção da teoria e da prática dos direitos humanos e fundamentais. Ela passa a ser considerada um dos pilares da legitimidade dos ordenamentos jurídicos, verdadeiro critério de aferição de justiça do direito positivo.

No campo trabalhista, como ficou assentado, o princípio da dignidade humana tem vários reflexos, como na proibição do trabalho infantil e do trabalho escravo, na vedação dos assédios moral e sexual, na vedação de tratamento discriminatório, na postulação da eficácia horizontal dos direitos fundamentais, entre inúmeras outras possibilidades.

No entanto, conforme se procurou demonstrar, o princípio da dignidade humana, em especial, no campo das relações de trabalho subordinado, não consegue escapar dos limites estruturais do modo de produção capitalista. Dessa forma, a pessoa humana, fim em si, ao adentrar nessas 
relações, transmuta-se em meio para um fim externo, a valorização do capital.

Assim, sem menosprezar a importância do reconhecimento e da aplicação do princípio da dignidade humana no campo das relações de trabalho, mesmo com os limites apontados, urge que se encontrem outras formas de sociabilidade, nas quais o princípio da dignidade humana possa se realizar mais intensamente.

\section{Referências}

ALEXY, Robert. Teoria dos direitos fundamentais. Tradução de Virgílio Afonso da Silva. São Paulo: Malheiros, 2008. 669 p. Título original: Theorie der Grundrechte.

ALEXY, Robert. Tres escritos sobre los derechos fundamentales y la teoría de los principios. Tradução de Carlos Bernal Pulido. Bogotá: Universidad Externado de Colombia, 2003. 152 p.

ANDRADE, José Carlos Vieira de. Os direitos fundamentais na Constituição Portuguesa de 1976. 2. ed. Coimbra: Almedina, 2001. AÑÓN ROIG, María José. Necesidades y Derechos: un ensayo de fundamentación. Madrid: Centro de Estudios Constitucionales, 1994. 350 p.

BARBOSA, Ana Paula Costa. A fundamentação do princípio da dignidade humana. In: TORRES, Ricardo Lobo (org.). Legitimação dos direitos humanos. Rio de Janeiro: Renovar, 2002.

BARZOTTO, Luiz Fernando. Pessoa e reconhecimento - uma análise estrutural da dignidade da pessoa humana. In: ALMEIDA FILHO, Agassiz; MELGARÉ, Plínio (org.). Dignidade da pessoa humana: fundamentos e critérios interpretativos. São Paulo: Malheiros, 2010. p. 39-67.

BILBAO UBILLOS, Juan María. ¿En que medida vinculan a los particulares los derechos fundamentales? In: SARLET, Ingo Wolfgang 
(org.) Constituição, direitos fundamentais e direito privado. Porto Alegre: Livraria do Advogado, 2010. p. 263-293.

BLOCH, Ernest. Derecho natural y dignidad humana. Tradução de Felipe González Vicén. Madrid: Dykinson, 2011. 557 p. Título original: Naturrech und menschliche Würde.

BOBBIO, Norberto. Direitos do homem e Sociedade. In: BOBBIO, Norberto. A era dos direitos. Tradução de Carlos Nelson Coutinho. Rio de Janeiros: Campus, 1992. p. 67-83.

CAMINO, Carmen. Direito individual do trabalho. 3. ed. Porto Alegre: Síntese, 2003.

CAMUS, Albert. O mito de Sífifo. Tradução de Ari Roitman e Paulina Watch. 13. ed. Rio de Janeiro: Bestbolso, 2020. 288 p. Título original: Le mythe de Sisyphe.

CAPELLA, Juan Ramón. Os cidadãos servos. Tradução de Lédio Rosa de Andrade e Têmis Correia Soares. Porto Alegre: Sergio Antonio Fabris, 1998. $230 \mathrm{p}$.

DELGADO, Maurício Godinho. Curso de direito do trabalho. 7. ed. São Paulo: LTr, 2008.

DELGADO, Maurício Godinho; DELGADO, Gabriela Neves.

A Reforma Trabalhista no Brasil. São Paulo: LTr, 2017.

DE MIGUEL BERIAIN, Iñigo. Consideraciones sobre el concepto de dignidad humana. Anuario de Filosofía del Derecho. Universidad Complutense de Madrid, Madrid, n. 21, p. 187-212, $2004 .$.

DUSSEL, Enrique. Ética da liberación en la edad de la globalización y de la exclusión. 4. ed. Madrid: Trotta, 2002.

EDELMAN, Bernard. O direito captado pela fotografia. Coimbra: Centelho, 1976.

ESPADA, Cinthia Maria da Fonseca. O princípio protetor do empregado e a efetividade da dignidade da pessoa humana. São Paulo: LTr., 2008. 
FERRAJOLI, Luigi. Derecho y garantias: la ley del más débil. Tradução de Perfecto Andrés Ibáñez. Madrid: Trotta, 1999. 180 p.

FERNÁNDEZ GARCÍA, Eusebio. Dignidad humana y cidadania cosmopolita. Madrid: Dykinson, 2001.

GARCIA, Marcos Leite. A contribuição de Christian Thomasius ao processo de formação do ideal dos direitos fundamentais. Revista Novos Estudos Jurídicos, Itajaí, v. 10, n. 2, p. 417-450, jul.-dez. 2005a.

GARCIA, Marcos Leite. O processo de formação do ideal dos Direitos Fundamentais: alguns aspectos da gênese do conceito. In: XVI CONGRESSO NACIONAL DO CONPEDI REALIZADO NA UNIVERSIDADE DE FORTALEZA UNIFOR (Fortaleza, CE). Anais [...]. Florianópolis: Fundação Boiteux, 2005b. v. 1. p. 19-31. Disponível em: http://www.publicadireito.com.br/conpedi/manaus/arquivos/anais/ XIVCongresso/052.pdf. Acesso em: 20 jan. 2020.

GENRO, Tarso. Direito individual do trabalho. 2. ed. São Paulo: LTr, 1994.

GOMES, Joaquim Benedito Barbosa. O Poder de polícia e o princípio da dignidade da pessoa humana na jurisprudência francesa. ADV Advocacia Dinâmica: seleções jurídicas, [S.l.], n. 12. p. 12-17, dez. 1996.

GONÇALVES, Rogério Magnus Varela. A dignidade da pessoa humana e o direito à vida. In: ALMEIDA FILHO, Agassiz; MELGARÉ, Plínio. Dignidade da pessoa humana: fundamentos e critérios interpretativos. São Paulo: Malheiros, 2010. p. 448-470.

GRAU, Eros Roberto. A ordem econômica na Constituição de 1988. 7. ed. São Paulo: Malheiros, 2002.

HABERMAS, Jürgen. Derecho natural y revolución. In: HABERMAS, Jürgen. Teoría y práxis: estúdios de filosofia social. 5. ed. Tradución de Salvador Mas Torrres. Madrid: Tecnos, 2008. p. 87-162. Título original: Theorie und Praxis. 
HÄBERLE, Peter. A dignidade humana como fundamento da comunidade estatal. In: SARLET, Ingo Wolfgang (org.). Dimensões da dignidade: ensaios de filosofia do direito e direito constitucional. Porto Alegre: Livraria do Advogado, 2005. p. 116-130.

HINKELAMMERT, Franz. Lo indispensable es inútil: hacía una espirutualidad de la liberación. San José (Costa Rica): Editorial Arlekín, 2012.

KANT, Immanuel. Fundamentação da Metafísica dos Costumes. In: KANT, Immanuel. Os Pensadores - Kant (II). Tradução de Paulo Quintanela. 2. ed. São Paulo: Abril Cultural, 1984. p. 103-162. Título original: Grundlegung zur Metaphysik der Sitten.

KANT, Immanuel. Doutrina do direito. 2. ed. Tradução Edson Bini. São Paulo: Ícone, 1993. Título original: Rechtslehre.

KASHIURA JR., Celso Naoto. Sujeito de direito e capitalismo. São Paulo: Outras Expressões; Dobra Universitária: 2014.

LIMA, Maria Rosynete Oliveira de. Devido processo legal. Porto Alegre: Sérgio Antônio Fabris, 1999.

LORENZETTI, Ricardo Luís. Fundamentos do Direito Privado. São Paulo: RT, 1998.

MARTÍNEZ-PUJALTE, Antonio Luis. Los derechos humanos como derechos inalienables. In: BALLESTEROS, Jesús. Derechos humanos: concepto, fundamentos, sujetos. Madrid: Tecnos, 1992. p. 86-99.

MARX, Karl. O capital: crítica da economia política. Tradução de Reginaldo Sant'Anna. Rio de Janeiro: Civilização Brasileira, 2008a. Livro I. v. 1.574 p. Título original: Das Kapital.

MARX, Karl. Contribuição à crítica da economia política. Tradução de Florestan Fernandes. São Paulo: Expressão Popular, 2008b. 288 p. Título original: Zur Kritik der Politischen Oekonomie.

MARX, Karl. Grundrisse: manuscritos econômicos de 1857-1858. Traducão de Nélio Schneider. São Paulo: Boitempo, 2011. 792 p. 
MIRANDA, Jorge. Manual de Direito Constitucional - Tomo IV:

Direitos Fundamentais. 4. ed. Coimbra: Coimbra Editora, 2004.

OLIVEIRA, Marcus Vinícius Xavier. Considerações em torno do princípio da dignidade da pessoa humana. 2002. Disponível em: www. jus.com.br. Acesso em: 20 nov. 2019.

PECES-BARBA, Gregorio. Las líneas de evolución de los derechos fundamentales. In: PECES-BARBA, Gregorio. Curso de Derechos Fundamentales: teoría general. Madrid: Universidad Carlos III de Madrid, 1995. p. 154-204.

PECES-BARBA, Gregorio. La dignidade de la persona humana desde la Filosofía del Derecho. 2. ed. Madrid: Dykinson, 2003.

PECES-BARBA, Gregorio. La libertad del hombre y el genoma. Derechos y Libertad. Revista del Instituto Bartolomé de las Casas. N. 2, año I, Universidad Carlos III de Madrid. p. 302-325. Oct. 1993-Mar 1994.

PECES-BARBA MARTÍNEZ, Gregorio. Reflexiones sobre la evolución histórica y el concepto de dignidad humana. In: ALMOGUERA CARRERES, Joaquín; et al. (org.). Desafíos actuales a los derechos humanos: la violencia de género, la inmigración y los medios de comunicación. Madrid: Universidad Carlos III de Madrid/Editorial Dykinson, 2005, p. 15-36.

PÉREZ LUÑO, Antonio Enrique. Derechos humanos, estado de derecho y constitucion. 8. ed. Madrid: Tecnos, 2003.

RABENHORST, Eduardo Ramalho. O valor da pessoa humana e o valor da natureza. In: ALMEIDA FILHO, Agassiz; MELGARÉ, Plínio.

Dignidade da pessoa humana: fundamentos e critérios interpretativos. São Paulo: Malheiros, 2010. p. 21-38.

RAMOSE, Mogobe B. Globalização e ubuntu. In: SANTOS, Boaventura de Sousa; MENESES, Maria Paula. Epistemologias do Sul. São Paulo: Cortez, 2010. p. 175-220.

RODRIGUES, Américo Plá. Princípios de direito do trabalho. Tradução de Wagner D. Giglio. São Paulo: LTr, 1978. 


\section{SARLET, Ingo Wolfgang. Dignidade da pessoa humana e direitos} fundamentais na Constituição Federal de 1988. 9. ed. Porto Alegre:

Livraria do Advogado, 2012.

SARMENTO, Daniel. Dignidade da pessoa humana: conteúdo, trajetórias e metodologia. Belo Horizonte: Fórum, 2016.

TEPEDINO, Gustavo. Temas de direito civil. 2. ed. Rio de Janeiro; São Paulo: Renovar, 2001.

Ipojucan Demétrius Vecchi é doutorando do Programa de Pós-Graduação Stricto Sensu em Ciência Jurídica da Universidade do Vale do Itajaí (UNIVALI). Mestre em Direito pela Universidade do Rio dos Sinos (UNISINOS). Professor do Curso de Graduação em Direito da Universidade de Passo Fundo (UPF). Advogado trabalhista.

E-mail: ipojucan@upf.br

Endereço profissional: Universidade de Passo Fundo, Faculdade de Direito, BR 285, Bairro de São José. Passo Fundo, RS. CEP 99052-900.

https://orcid.org/0000-0001-7998-1304

Marcos Leite Garcia é doutor em Direitos Fundamentais (2000) e Master em Direitos Humanos (1990), ambos os cursos realizados no Instituto de Direitos Humanos da Universidade Complutense de Madrid, Espanha. Realizou estágio pós-doutoral na Universidade de Santa Catarina entre 2011e 2012. Desde 2001 professor do Programa de Pós-Graduação Stricto Sensu em Ciência Jurídica, Cursos de Mestrado e Doutorado, e do Curso de Graduação em Direito da Universidade do Vale do Itajaí (UNIVALI) - Santa Catarina. Da mesma maneira, desde 2015 professor do Programa de Pós-Graduação em Direito, Curso de Mestrado, da Universidade de Passo Fundo (UPF) - Rio Grande do Sul.

E-mail:mleitegarcia@terra.com.br

Endereço profissional: Universidade do Vale do Itajaí, Programa de PósGraduação Stricto Sensu em Ciência Jurídica. Rua Uruguai, n. 458, Centro, Itajaí, SC. CEP 88302-901.

https://orcid.org/0000-0003-3299-3556 
Liton Lanes Pilau Sobrinho é doutor em Direito pela Universidade do Vale do Rio dos Sinos - UNISINOS (2008). Mestre em Direito pela Universidade de Santa Cruz do Sul - UNISC (2000). Possui graduação em Direito pela Universidade de Cruz Alta (1997). Professor dos cursos de Mestrado e Doutorado no Programa de Pós-Graduação Stricto Sensu em Ciência Jurídica da Universidade do Vale do Itajaí. Professor do Programa de Pós-Graduação Stricto Sensu Mestrado em Direito da Universidade de Passo Fundo. Coordenador do PPGDireito da Universidade de Passo Fundo. Pós-doutor em Direito pela Universidade de Sevilha, US. Espanha.

E-mail: liton@upf.br

Endereço profissional: Universidade do Vale do Itajaí, Programa de PósGraduação Stricto Sensu em Ciência Jurídica. Rua Uruguai, n. 458, Centro, Itajaí, SC. CEP 88302-901.

https://orcid.org/0000-0001-5696-4747 